\title{
Ancient Chinese Astronomical Analysis of the Chapter, Wigi Haeng in Youngchu (Spiritual Pivot)
}

\author{
Woosen Ur \\ Department of Third Medicine, Professional Graduate School of Korean Medicine, Wonkwang University

\section{영추, 위기행편에 대한 중국 고천문학적 분석} \\ 어우센 ${ }^{(1)}$
}

원광대학교 한의학전문대학원 제 3 의학과

\begin{abstract}
Objectives: This research aimed to 1) analyze the true meanings of the chapter, 'Wigi Haeng (Wei Qi Xing), the movement of guard q' in Youngchu (Ling Shu) from the point of view of ancient Chinese Astronomy, 2) calculate the speed of Wigi over 24 Chinese seasons, 3) analyze the true meaning of daytime and nighttime in the chapter. Methods: 1) The chapter 'Wigi Haeng' was analyzed using concepts of ancient Chinese astronomy, 2) the records of angular distances of 28 constellations in the Book of Han (Han $\mathrm{Shu}$ ) were used to analyze the meanings, and 3) the records of lengths of daytime and nighttime in the Book of Hou Han (Hou Han $\mathrm{Shu}$ ) were used to calculate the speed of Wigi. Results: 1) The author of the chapter 'Wigi Haeng' did not consider the irregularity in the angular distances of the 28 Chinese constellations (Su). 2) The commentary in the Huangjenaegyong Taeso (Huang Di Nei Jing Tai Su) about the constellations in the chapter is correct. 3) The speed of Wigi changes in daytime and nighttime depending on the seasons. 4) When the speed of Wigi increases in daytime, the speed in nighttime decreases, and vice versa. 5) The beginning of daytime in 'Wigi Haeng' is not the time of sunrise but the time of dawn (2.5 Gak before sunrise). The nighttime ends 2.5 Gak after sunset. Conclusions: 1) The chapter 'Wigi Haeng' demonstrates the ancient astronomical point of view on the universe and the movement of Wigi. The speed of Wigi is variable. 2) This chapter does not address the irregularity in the angular distances of the $28 \mathrm{Su}$. 3) More research is needed on the meaning of daytime and nighttime in 'Wigi Haeng'.
\end{abstract}

Key words : Wigi, Chinese constellation, ancient astronomy, Spiritual Pivot, Yellow Emperor, Ling Shu

\section{Introduction}

Astronomy is one of the oldest areas of study and it dominated the theories that ancient people employed to understand the universe. Ancient constellations, concepts of time, and calendars reflect their views on the movement of the universe. Ancient Chinese people thought that humans were connected to the universe and that the movement of the universe influenced the human body and mind. Since ancient times, Chinese medicine especially has focused on the principles of communication between humans and the universe $^{1)}$. It is necessary to research these ancient astronomical beliefs to understand the true meanings of classical texts on Chinese medicine.

The Yellow Emperor's classic of internal medicine text, the Huangjenaegyong (黃帝內經, Huang Di Nei Jing, Inner

Received November 10, 2019, Revised December 10, 2019, Accepted December 10, 2019

Corresponding author: Woosen Ur

Department of Third Medicine, Professional Graduate School of Korean Medicine, Wonkwang University, 460 lksandae-ro, Iksan 54538, Korea

Tel: +82-63-850-5193 4, Fax: +82-63-850-7324, E-mail: taodasmente@gmail.com

(C) This is an open access article distributed under the terms of the Creative Commons Attribution Non-Commercial License (http://creativecommons.org/licenses/ by-nc/4.0) which permits unrestricted non-commercial use, distribution, and reproduction in any medium, provided the original work is properly cited. 
Canon of the Yellow Emperor) is a grand book of ancient Chinese medicine that explains how the universe and the human body are connected and how the movements of the universe and the human Qi (氣) communicate. The text is divided into two classics: Somun (素問, Su Wen) and Youngchu (靈樞, Ling Shu, Spiritual Pivot, Yellow Emperor's Canon of Acupuncture). The "Wigi Haeng" chapter (衛氣行, "the movement of guard qi") appears in the ninth volume of Youngchu and in the $12^{\text {th }}$ volume of the Huangjenaegyong Taeso (黄帝內經太素, Huang Di Nei Jing Tai Su, [“Taeso” in this article]). The Huangjenaegyong uses ancient astronomical knowledge to explain the physiology, pathology, and treatment of acupuncture. The "Wigi Haeng" chapter is one example of the use of the ancient astronomical concepts of time, seasons and constellations to explain the movement of Wigi (衛氣, guard qi) and the universe. Therefore, to understand the original meanings of the chapter, it is necessary to research the ancient concepts pertaining to time and seasons. In Chinese medicine, Wigi is a kind of Qi-energy (氣) that flows through the human body and protects the body from external pathogens. According to the chapter, Wigi circulates 50 times per day: 25 times in the Yang portion during the daytime, and 25 times in the Yin portion (the deeper portion of the human body) during the night. The chapter insists that the acupunctural treatments must follow the movement of Wigi. In the chapter, the Yellow emperor asks "The presence of the guard qi in the human body, their ascending and descending, their coming and going, does not adhere to a definite timetable. If one wishes to inspect these qi to pierce them, how is that done? (黃帝曰, 衛氣之在於身也, 上下往來不以期, 候氣而刺之, 奈何? ${ }^{22}$. The answer became the main idea of this chapter. The chapter emphasizes that the diagnosis and insertion of the needles have to follow the concepts of time and the movement of Qi, The chapter states, "One follows the different lengths of a day as norm and pierces accordingly. When the time sections are carefully observed, the course of a disease can be predicted. If one neglects the time sections and acts contrary to the observations, none of the hundred diseases will be curable. (隨曰之 長短, 各以爲紀以刺之. 謹候其時, 病可與期, 失時反候者 百病不
治”2). The chapter insists the location of Qi is important in treatment. The chapter additionally states, "Hence, to carefully observe where the qi is and then pierce them, that is called, 'meeting the time'. (是故謹候氣之所在而刺之, 是謂逢 時)"2). Later in the Jin (金) dynasty, the principles of treatment following time and Qi formed the fundamental ideas of the time-based acupunctural treatments (Jaoyuju acupuncture, 子午流注銊法).

According to modern research, the Huangjenaegyong was written in about first century $\mathrm{BCE}^{3)}$, and during the Spring and Autumn periods and the Warring States period(春秋戰國時 代, 770 221 BCE), Chinese astronomy began to be mentioned in Chinese historical records. To make the calendar, ancient Chinese astronomers observed the movements of the sun, moon, and other celestial objects like stars. To calculate the altitude of the sun, they used a special pole like the gnomon or Pyo (表, Biao $)^{4)}$ to measure the lengths of shadows. They used time units called Gak (刻, Ke, literally means mark). Time was measured using a clepsydra, a kind of waterdropping clock'. The "Wigi Haeng" chapter mentions that one day is 100 Gak. The chapter states, "In the course of one day and one night, the water in the clepsydra descends by 100 marks. (一日一夜, 水下百刻)"2).

Moreover, to determine the position of the sun they divided the celestial hemisphere into 28 divisions called 28 $\mathrm{Su}$ (宿). The "Wigi Haeng" chapter explains the movement of Wigi using terms of $28 \mathrm{Su}$ and the time unit, Gak, proving that at the time of writing the Youngchu, astronomers and the author of the chapter were aware of the $28 \mathrm{Su}$ and measured time with unit, Gak. Therefore, to understand the sentences in the chapter, it is necessary to study the ancient system of $28 \mathrm{Su}$ and Gak.

This article analyzes the "Wigi Haeng" chapter using ancient Chinese astronomical concepts to more clearly understand the original meanings of the chapter. Moreover, according to the chapter, the lengths of day and night changed depending on the seasons. In this article, the speed of Wigi, which varied depending on the seasons is calculated. To calculate the speed of Wigi in various moments in one year, the records of daytime and nighttime following the tra- 
ditional Chinese 24 seasons (24節氣) in the Book of Hou Han (後漢書, Huhanseo) were used. The 24 seasons system divides one year into 24 seasons and it shows the change of the lengths of daytime and nighttime in more detail than the modern system that uses four seasons.

\section{Materials and Methods}

\section{Data sources}

(1) The English book Huang Di Nei Jing Ling Shu (by Unschuld, P.) was used as the source translation for the original text of the "Wigi Haeng" chapter. This book was published by the University of California Press in 2016. ISBN 978-0-520-29225.

(2) The constellations characters data from the excavation of the Zeng Hou Yi tomb (曾候乙墓), the records from the Book of Han (漢書, Hanseo), the Annals of Lu Bu Wei (呂氏春 秋, Yeosichunchu), The Book of Rites (禮記, Yegi), Huainanzi (淮南子, Hyonamja) and Records of the Grand Historian (史記, Sagi) were used to research the changes in the characters of constellations.

(3) To analyze the angular distances of each $28 \mathrm{Su}$, the records in the Book of Han were used.

(4) Commentary from Huangjenaegyong Taeso (黄帝內經太 素, Huang Di Nei Jing Tai Su, Commentaries of the Yellow Emperor's classic of internal medicine by Yang Shang Shan [楊上善]) were used. In this article, Taeso means Huangjenaegyong Taeso.

(5) The records of the lengths of daytime and nighttime following the 24 seasons in the Book of Hou Han (後漢書) were used to calculate the speed of Wigi.

\section{Analysis methods}

(1) The Chinese characters for $28 \mathrm{Su}$ (constellations, 宿) have changed throughout the different eras. To track the writing period of the chapter, the characters of the constellations in the "Wigi Haeng" chapter and those in other ancient classics were compared

(2) Each of the $28 \mathrm{Su}$ has different angular distances. By calculating the sum total of the angular distances in each direction, we found that the author of the chapter did not consider the irregularity of each $28 \mathrm{Su}$. Dividing the sum total of the angular distances in each direction by 2 , the due directions (due east, due west, due north and due south) were found and could be used to verify the sentences regarding the directions in the "Wigi Haeng" chapter.

(3) Wigi circulates 25 times in the daytime and 25 times in the nighttime. To calculate the speed of Wigi in both the daytime and nighttime, the 25 circulations were divided by the lengths of daytime and nighttime. In the "Wigi Haeng" chapter, we noticed that the author of the chapter knew that the speed of Wigi changes although he did not mention it directly. Instead he only mentioned the changes in the lengths of daytime and nighttime in relation to seasons. Because the number of cycles that Wigi completes during the daytime and nighttime are fixed to 25 cycles each, it is possible to calculate the speed of Wigi, and also to see how the speed changes depending on the 24 seasons.

\section{Terms used}

(1) The word, Wigi is "guard qi" in the English translation source book. It is translated as "wei-energy" in other translated texts.

(2) The word "Su" (宿) means constellation.

(3) The chosen English translation text uses the word "mark" as the literal translation for the word "Ke" (刻, Gak) In this article the Korean pronunciation "Gak" (刻) is used for the same meaning, which is the unit of time. One day is $100 \mathrm{Gak}$.

(4) Some Chinese characters were used in the English translation text for a clearer meaning.

(5) Essentially, Korean and Chinese pronunciations are used for Chinese words. The English translation terms are used if these terms are internationally recognized. However, if the terms are based more on Chinese culture, the Chinese pronunciation are used primarily (such as the names of places, people, and constellations).

(6) Ancient Chinese astronomy related contents were primarily analyzed. 


\section{Results}

\section{The concepts of 12 months, 12 jin (辰, chen, unit for the divisions of a day), and the $28 \mathrm{Su}$ in ancient Chinese astronomy}

Original text: "A year has twelve months. A day has twelve double-hours (辰, jin, chen).” (歲有十二月, 日有十二辰 $)^{2}$.

Qi Bo (歧伯, Gibak) explains that one year has 12 months and that one day has 12 jin. In ancient China, people used the lunisolar calendar. In this system one month equals to 29 days. The number 29 came from lunation (lunar month). The lunation period is about 29.5306 days and Chinese people used this 29 day cycle to divide one year ${ }^{6}$. When the 28 constellations were decided in China (or at least when the chapter of "Wigi Haeng" chapter was written), Chinese astronomers already knew that one year was not 365 days exactly but was actually 365.25 days ${ }^{7}$. If one divides 365.25 days by 29 days, this results in approximately 12.594 months. Therefore, they sometimes used the intercalation system of counting 30 days as one month to have precisely 12 months in one year. With this system, one month is sometimes 29 days in length and sometimes 30 days $^{6}$. Because Chinese astronomers understood that one year has 365.25 days, the perfect Chinese circle is 365.25 degrees. However, in modern mathematics, the perfect circle is 360 degrees. Because of this difference, one degree using the ancient Chinese system is approximately 0.9856 of a degree in relation to the modern system of mathematics. Therefore, the angular distances of constellations in this article are not equivalent to modern measurements. To convert ancient Chinese degrees into modern ones, the measurement must be divided by $0.9856^{7}$.

In the "Wigi Haeng" chapter, each day is divided into 12 jin; the word jin is simply a kind of unit used to divide one day into sections. Because one day has 24 hours, one jin is equivalent to two hours. The number 12 may came from the 12 months of the year. Chinese may have decided to divide each day into 12 sections because each year was divided into 12 months. They might have thought that one day is like a small year. Because there are four seasons in a year, each day also has four divisions : dawn, morning, afternoon, and night.

\section{Changes of the names of constellations and the writing period}

In the "Wigi Haeng" chapter there are some names for different constellations. These constellations are Fang (房, Bang), Mao (昴, Myo), Xu (虛, Heo), Zhang (張, Jang), Bi (畢, Pil), and Xin (心, Sim).

Original text: "The celestial circle includes 28 constellations. On each side there are seven stars (Su, 宿, constellation). Four times seven are 28 constellations. The line from the constellation, fang (房) in the East to the constellation, mao (昂) in the west constitutes the weft. The line from the constellation, xu (虛) in the North to the constellation, zhang (張) in the South constitutes the warp. The fact is: (The constellations) fang (房) to bi (畢), are yang. (The constellations) mao (昂) to xin (心) are yin” (天周二十八宿, 而一面七 星, 四七二十八宿. 房昂爱緯, 虛張爲經. 房至畢爲陽, 昂至心爲陰 $)^{2)}$.

The terms weft and warp in the original English text are used as the translation for the Chinese characters, Wei (緯, Ui) and Jing (經, Gyong), respectively. Unschuld, P. commented on these words: "The constellation fang lies in the East and the constellation mao in the West, the line from the East to the West is a horizontal line and hence it is said : fang and mao constitutes the weft thread. The constellation $\mathrm{xu}$ lies in the North and the constellation zhang lies in the South. The line from the North to the South is a vertical line. Hence it is said: $x u$ and zhang constitutes the warp thread"2). The words, latitude and longitude are used in the same meaning as the translated book by Wu, L. and Wu, $\mathrm{Q}^{8}$.

To understand the changes in the names of these constellations, it is necessary to research the earliest forms of the characters for the $28 \mathrm{Su}$. The earliest record of the characters for the $28 \mathrm{Su}$ was found in 1978, through the archaeological excavation of the tomb of Zeng Hou Yi at Lei Gu Dun in the Sui area of Hu Bei province (湖北省随县 擂鼓敦 曾侯乙墓, Hobukseongsuhyon, Ryogodon, Zeunghueulmyo) in China. The ancient names of the $28 \mathrm{Su}$ were found on the box cover and coated with lacquer. They were from about 433 BCE (the early stages of the Warring States period in China, 戰國時代初, Jeongukusidaecho). All of the names of the 
$28 \mathrm{Su}$ are written in the Zhuan style (䇡文, Jeonmun, Jeonseo) of Chinese characters'). If the Zhuan style characters are transformed into Kai style (楷書, Haeseo), the characters of Fang, Mao, Xu, Zhang, Bi and Xin are then correspondingly written as 方 (Fang, Bang), 矛 (Mao, Mo), 虛 (Xu, Heo), 張 (Zhang, Jang), 縪 (Bi, Pil) and 心 (Xin, Sim). These characters are slightly different from those in the "Wigi Haeng" chapter of Youngchu. Fang, Mao and Bi have different character forms in the "Wigi Haeng" chapter. From the fact that the names of the constellations in the chapter are different from the excavation, the writing period of the chapter is therefore not earlier than 433 BCE. When emperor Wu of the Han dynasty (漢武帝, Hanmuje) made the grand primary calendar (太初曆, Taechoryok), he ordered the alchemist Guang Du (方 士廣都, Bangsa Guangdo) to decide the correct divisions of the $28 \mathrm{Su}$ in the celestial hemisphere and these official characters for the $28 \mathrm{Su}$ are shown in the calendar section (律曆志, Yulryokji) in the Book of Han (漢書, Hanseo, $82 \mathrm{AD})^{7}$.

The $28 \mathrm{Su}$ characters in the Book of Han are 角 (Jiao, Gak), 元 (Kang, Hang), 氏 (Di, Jeo), 房 (Fang, Bang), 心 (Xin, Sim), 尾 (Wei, Mi), and 箕 (Ji, Gi) for the eastern constellations; 斗 (Dou, Du), 牛 (Niu, Wu), 女 (Nu, Yeo), 虛 (Xu, Heo), 危 (Wei, Ui), 營室 (Ying Shi, Yeongsil), 壁 (Bi, Byeok) for the north; 奎 (Kui, Gyu), 婁 (Lou, Ru), 胃 (Wei, Ui), 昂 (Mao, Myo), 畢 (Bi, Pil), 觜 (Zi, Ja), 參 (Shen, Sam) for the west; and 井 (Jing, Jeong), 鬼 (Gui, Gwui), 柳 (Liu, Ryu), 星 (Xing, Seong), 張 (Zhang, Jang), 翼 (Yi, Yik), and 軫 (Zhen, Jin) for the south. The characters for three of the six constellations, Fang, Mao, $\mathrm{Xu}$, Zhang, Bi (畢, Pil) and Xin are different from the characters excavated from the tomb of Zeng Hou Yi. The character for Fang changed from 方 (Fang, Bang) to 房 (Fang, Bang) and the character for Mao changed from 矛 (Mao, Mo) to 昴 (Mao, Myo). The characters for 虛 (Xu, Heo) and 張 (Zhang, Jang) did not change. The character for Bi changed from 縪 (Bi, Pil) to 畢 $(\mathrm{Bi}, \mathrm{Pil})$ and the character for 心 (Xin, Sim) did not change. Other classics from that time have similar characters but some are different. For example, the Annals of $\mathrm{Lu} \mathrm{Bu}$ Wei (呂氏春秋, Yeosichunchu, 239 BCE) includes the characters 房 (Fang, Bang), 昂 (Mao, Myo), 虛 (Xu, Heo), 張 (Zhang, Jang), 畢 (Bi, Pil) and 心 (Xin, Sim) for the constellations, Fang, Mao, Xu, Zhang, Bi and Xin. The Book of Rites (禮記, Yegi, writing period is unclear but probably the Warring States period and early Han periods) includes the characters 房 (Fang, Bang), (not shown for Mao), 虛 (Xu, Heo), (not shown for Zhang), 畢 (Bi, Pil), 火 (Huo, Hwa) for the constellations. The characters for Mao and Zhang are not shown, and the character of 火 (Huo, Hwa) is shown for Xin. Huainanzi (淮南子, Hyonamja, 139 BCE) has these characters: 房 (Fang, Bang), 昂 (Mao, Myo), 虛 (Xu, Heo), 張 (Zhang, Jang), 畢 (Bi, Pil), and 心 (Xin, Sim). Records of the Grand Historian (史記, Sagi, 86 BCE) show 房 (Fang, Bang) for Fang, 昂 (Mao, Myo) and 留 (Liu, Ryu) for Mao, 虛 (Xu, Heo) for Xu, 張 (Zhang, Jang) and 七星 (Qi Xing, Chilsung) for Zhang, 濁 (Zhuo, Tak) and 畢 (Bi, Pil) for Bi, and 心 (Xin, Sim) for Xin ${ }^{7}$. Compared to the characters from the classic texts, the characters of Su in the "Wigi Haeng" chapter are more similar to those from the Book of Han (漢書, Hanseo), the Annals of Lu Bu Wei (呂氏春秋, Yeosichunchu, 239 BCE) and Huainanzi (淮南子, Hyonamja, 139 BCE). This fact matches the writing period of Huangjenaegyong, which is first century BCE, as modern scholars insist.

\section{Each of the 28 Su have irregularly different an- gular distances}

Original text: "The celestial circle includes 28 constellations. On each side there are seven stars (constellations). Four times seven are 28 constellations” (天周二十八宿, 而一面 七星, 四七二十八星 $)^{2)}$.

It is clear that the $28 \mathrm{Su}$ system was already known when this chapter was written. In the chapter, one aspect has seven $\mathrm{Su}$, and there are four aspects. Therefore, there are $28 \mathrm{Su}$ total (seven times four). It is not clear why they used the number 28 but perhaps it came from the lunar orbiting period (27.32 days), which is closer to 27 than 28 . However, they may have chosen 28 because it can be divided equally into four directions ${ }^{6}$.

According to the research of Oosaki Shouji (大崎正次), the complete formation of the $28 \mathrm{Su}$ system must have occurred before the late Spring and Autumn periods and the Warring States period (春秋戰國時代末, Chunchujeonguksidaecho) ${ }^{7)}$. 
When the Han dynasty alchemist Guang Du (方士廣都, Bangsa Guangdo) determined the correct divisions of the $28 \mathrm{Su}$ in the celestial hemisphere by order of Emperor Wu of Han (漢 武帝, Hanmuje), the alchemist measured the correct angular distances of the $28 \mathrm{Su}^{7}$. This meant that the angular distances of the $28 \mathrm{Su}$ were not equal. In fact, they differed from one another in an irregular fashion. This was because the regions of the $28 \mathrm{Su}$ were defined by stars and not by dividing the sky into 28 equal divisions ${ }^{10)}$. Ancient Chinese used two bright opposite stars to define each of the $28 \mathrm{Su}$. The opposite star is the star that is located in the opposite direction with a 180 degree difference in the right ascension ${ }^{6}$ (Astronomical term to locate the stars). Therefore, the $28 \mathrm{Su}$ system does not divide the sky into equal areas but instead divides it into 28 constellations. The angular distances that the alchemist Guang Du measured are shown in the Book of Calendar (暦書, Yeokseo) in the Records of the Grand Historian (史記, Sagi) and the "Calendar section" (律曆志, Yulryokji) of the Book of Han (漢書, Hanseo) $)^{7}$. In these texts we can see that the angular distances for each of the $28 \mathrm{Su}$ are not equal and are all irregularly different, as shown in Table $1^{77}$. The units are ancient Chinese degrees (equivalent to 0.9856 degrees in modern mathematics).

Because the total sum of the angular distances is 365 degrees (less than 365.25 degrees), Oosaki Shouji added 0.25 degrees to Dou (斗, Du) to make it 26.25 degrees. However, in this study we followed angle measurements according to the original records from the Book of Han. The difference in angular distances varies from a minimum of two degrees to a maximum of 33 degrees. The maximum difference between two Su is 31 degrees. The sizes of the 28 Su are ir- regular. However, the Su in directions opposite from one another have similar sizes, such as the Jiao (角, Gak)-Kui (奎, Gyu), Kang (元, Hang)-Lou (婁, Ru), Di (氐, Jeo)-Wei (胃, Ui), Fang (房, Bang)-Mao (晶, Myo), Wei (尾, Mi)-Bi (畢, Pil), Ji (箕, Gi)-Zi (觜, Ja), Dou (斗, Du)-Jing (井, Jeong), Niu (牛, Wu)-Gui (鬼, Gwui), Nu (女, Yeo)-Liu (柳, Ryu), Xu (虛, Heo)-Xing (星, Seong), Wei (危, Ui)-Zhang (張, Jang), Shi (室, Sil)-Yi (翼, Yik), Bi (壁, Byeok)-Zhen (軨, Jin). This means that the 28 Su were decided using two opposite indicator stars that have 180 modern degrees of difference in the right ascension between them. The western stars and the eastern stars are paired with one another. The northern and the southern stars are similarly paired. Xin (心, Sim) and Shen (參, Sam) are not paired, which seems to be due to the precession movement of the Earth').

\section{Analysis of the commentary from the Taeso}

Original text: "The line from the constellation, fang (房) in the East to the constellation, mao (昴) in the west constitutes the weft. The line from the constellation, xu (虚) in the North to the constellation, zhang (張) in the South constitutes the warp" (房昂爲緯, 虛張爲經 ${ }^{2}$.

Commentary from Taeso: "Zhang (張, Jang) is an error and should be Xing (星, Seong) because it is located at the center of the southern seven Su” (經云虛張爲經者 錯矣. 南方七宿 星爲中 也) ${ }^{11)}$.

In the original text, the weft means the Wei (緯, Ui) line, which is the latitude line. The warp means the Jing (經, Gyong) line, which is the longitude line. Taeso notes that Zhang is an error and should be changed to Xing because Xing is located at the center of the southern seven Su (the

Table 1. Angular Distances of $28 \mathrm{Su}$ in the Book of Han (漢書)

\begin{tabular}{|c|c|c|c|c|c|c|c|}
\hline East & Jiao 角 & Kang 六 & Di 氏 & Fang 房 & Xin 心 & Wei 尾 & $\mathrm{Ji}$ 箕 \\
\hline Angular distance & 12 & 9 & 15 & 5 & 5 & 18 & 11 \\
\hline North & Dou 斗 & $\mathrm{Niu}$ 牛 & $\mathrm{Nu}$ 女 & Xu 虛 & Wei 危 & Shi 室 & $\mathrm{Bi}$ 壁 \\
\hline Angular distance & 26 & 8 & 12 & 10 & 17 & 16 & 9 \\
\hline West & Kui 奎 & Lou 婁 & Wei 胃 & Mao 昂 & Bi 畢 & Zi 觜 & Shen 參 \\
\hline Angular distance & 16 & 12 & 14 & 11 & 16 & 2 & 9 \\
\hline South & Jing 井 & Gui 鬼 & Liu 柳 & Xing 星 & Zhang 張 & Yi 翼 & Zhen 軨 \\
\hline Angular distance & 33 & 4 & 15 & 7 & 18 & 18 & 17 \\
\hline
\end{tabular}


center of the south) ${ }^{11)}$. According to the original text, Fang is located at the center of the east, Mao at the center of the west, $\mathrm{Xu}$ at the center of the north, and Zhang (Xing in the Taeso) at the center of the south.

To see how precisely each direction is determined, the sum total of angular distances for each direction is calculated. The sum of the angular distances of the seven $\mathrm{Su}$ in the eastern direction is 12 (Jiao, 角)+9 (Kang, 元)+15 (Di, 氏 +5 (Fang, 房)+5 (Xin, 心)+18 (Wei, 尾)+11 (Ji, 箕)=75 degrees. The sum for the northern direction is 26 (Dou, 斗)+8 (Niu, 牛)+12 (Nu, 女)+10 ( $\mathrm{Xu}$, 虛)+17 (Wei, 危)+16 (Shi, 室)+9 (Bi, 壁)=98 degrees. The sum for the western direction is 16 (Kui, 奎)+12 (Lou, 婁)+14 (Wei, 胃)+11 (Mao, 昂)+16 (Bi, 畢)+2 ( $\mathrm{Zi}$, 觜)+9 (Shen, 參)=80 degrees. The sum for the southern direction is 33 (Jing, 井)+4 (Gui, 鬼)+15 (Liu, 柳)+7 (Xing, 星)+18 (Zhang, 張)+18 (Yi, 翼)+17 (Zhen, 軫)=112 degrees. Table 2 shows the sum of the angular distances in each direction. The angular distances for each direction are not equal and the differences between them are large. The biggest difference is between the south and the east, which has a difference of 37 degrees. This occurs because the $28 \mathrm{Su}$ were not decided by simply dividing the celestial hemisphere into 28 parts. If the $28 \mathrm{Su}$ had been decided by dividing the celestial hemisphere into 28 equal parts, each Su would have had approximately 13.04 degrees of angular distance (365.25/ $28=13.04$ degrees), and each direction would have had an angular distance of (approximately) 91.31 degrees (365.25/ 4=91.31 degrees).

This means that determining the location of the center of each direction simply by using the $28 \mathrm{Su}$ system can cause an error because the angular distances of the 28 Su vary so irregularly. However, from the astronomical calculations, the middle points of the sum of the angular distances in each aspect indicate exactly the four directions at the time of

Table 2. Sum Total of Angular Distances in Each Direction.

\begin{tabular}{ccccc}
\hline Directions & East & North & West & South \\
\hline $\begin{array}{c}\text { Sum total of angular } \\
\text { distances of } 7 \text { constellations }\end{array}$ & 75 & 98 & 80 & 112 \\
\hline Unit: Chinese degrees. & & & & \\
\hline
\end{tabular}

dawn on the day of the spring solstice ${ }^{9)}$. The middle point of the 75 degrees in the eastern seven Su exactly indicates the due East, and other middle points in each direction indicate the correct directions as well. Considering the movement of precession of the Earth, these four directions match the period of $1200 \mathrm{BCE}$. This means the four directions were not decided by the $28 \mathrm{Su}$, but that the $28 \mathrm{Su}$ were determined after the four directions were determined".

Xing (星) is located at the fourth Su in the southern seven Su; therefore, it could be located in the middle. However, it is not very clear if the author of the Taeso really knew the direction of due south or had simply considered that because Xing is at the fourth $\mathrm{Su}$, it must be in the middle of seven $\mathrm{Su}$. From the sentence "Xing is located at the center of the southern seven Su (南方七宿 星爲中也)” in Taeso, it seems that the number seven was especially noted. Therefore, the author of the Taeso seemed to conclude that Xing was located at the middle simply because it was fourth Su.

It is possible to calculate the middle point by dividing the sum total of the angular distances in the south by 2 . The sum is 112 degrees in the south and the middle point is at 56 degrees from both the first Su and the last Su in the southern aspect. The middle point calculated is located at the area of Xing (星), which means that the original text of the "Wigi Haeng" chapter showed an error, as noted in the Taeso, demonstrating that the commentary from Taeso was correct.

\section{The author of the chapter considered that the $28 \mathrm{Su}$ all have the same angular distances}

Original text: "The fact is: (The constellations) fang to bi are yang. (The constellations) mao to xin are yin. Yang controls the day; yin controls the night" (房至畢爲陽, 昂至心爲 陰, 陽主畫, 陰主夜 $)^{2)}$.

Master Zhang Zhi Cong (張志聰), Ma Shi (馬蒔) and Jing Yue (景岳) thought that Yin and Yang were each divided by 14 Su. The region from Fang (房) to Bi (畢) through the east, south, and west is Yang, and the region from Mao (昂) to Xin (心) through the west, north, and east is Yin ${ }^{12}$. This is the big division of Yin and Yang in the celestial hemisphere and is decided by the directions. The half of the celestial hemi- 
sphere that includes the south is Yang, and the other half that includes the north is Yin. The sum total of the angular distances of the Yang area is Fang (房, 5)+Di (氏 15)+Kang (元, 9)+Jiao (角, 12)+Zhen (輍, 17)+Yi (翼, 18)+Zhang (張, 18)+Xing (星, 7)+Liu (柳, 15)+Gui (鬼, 4)+Jing (井, 33)+Shen (參, 9)+Zi (觜, 2)+Bi (畢, 16)=180 degrees. The sum total of the angular distances of the Yin region is Mao (昴, 11)+Wei (胃, 14)+Lou (婁, 12)+Kui (奎, 16)+Bi (壁, 9)+Shi (室, 16)+Wei (危, 17) $+\mathrm{Xu}$ (虚, 10) $+\mathrm{Nu}$ (女, 12) +Niu (牛, 8)+Dou (斗, 26)+Ji (箕, 11)+Wei (尾, 18)+Xin (心, 5)=185 degrees. According to these calculations, the Yang area is five degrees smaller than the Yin area. However, it is not likely that the author of the chapter thought that the Yang area was smaller than the Yin area because throughout the history of Chinese medicine, the principle of equilibrium between Yin and Yang was a primary philosophy. However, Master Zhu Dan Xi (朱丹溪) insisted that in nature, the Yin was likely to be less than the Yang. To prove this, he used the fact that the phases of the moon change but the sun does not change. However, Master Jing Yue (景岳) emphasized the importance of the Yang ${ }^{13}$. However, Master Jing Yue did not mention this idea in his commentary on this chapter. The five degrees of difference between the Yin and the Yang area may simply occur because the sizes of the $28 \mathrm{Su}$ are all different.

\section{The speed of Wigi changes depending on the length of the daytime and nighttime, and the seasons}

Original text: "The fact is: The movement of the guard qi completes fifty circulations during one day and one night. During day time they move through the yang realm and completes 25 circulations. During the night they move through the yin realm and complete 25 circulations" (故 衛氣之 行, 一日一夜五十周於身, 畫日行於陽二十五周, 夜行於陰二十五周 $)^{22}$.

Taeso and Master Jing Yue noted that the Wigi circulates 50 times a day: 25 times in the Yang portion in the daytime, and 25 times in the Yin portion in the nighttime ${ }^{11,12)}$.

At the time of Huang Di (黃帝, Huangje, Yellow Emperor), the interval between one midnight and the next midnight was divided into 100 equal parts, which were called Gak (刻, Ke, mark $)^{14)}$. One day was equal to $100 \mathrm{Gak}$ and $1 \mathrm{Gak}$ was approximately 0.24 hours. The record of the time unit, Gak appears in the Book of Han (漢書, $82 \mathrm{AD}$ ). The official history book, the Book of Hou Han (後漢書), which describes the history of the Hou Han dynasty (25 220 AD) includes a more detailed description of time unit, Gak. At the time the Book of Hou Han was written, one day was equal to $100 \mathrm{Gak}$ and 1 Gak was made up of 10 Bun (分, fen) $)^{5}$. During this period, people used the water-dropping clepsydra to measure time. It is necessary to understand what daytime and nighttime mean in the chapter. The modern meaning of daytime is the period between the time when the sun rises and when it goes down. However, at the time of Huang Di and when the Book of Hou Han was written, daytime included a 2.5 Gak period before the sun rose and a $2.5 \mathrm{Gak}$ period after the sun went down; 2.5 Gak is equal to about 36 minutes today. Because of this, daytime in the Book of Hou Han was 5 Gak longer than modern daytime, and nighttime was 5 Gak shorter, ${ }^{5,14)}$. In addition, the lengths of daytime and nighttime changed depending on the seasons. According to Masters Zhang Zhi Cong (張志聰), Ma Shi (馬蒋), and Jing Yue (景岳), the author of the "Wigi Haeng" chapter understood that the lengths of daytime and nighttime changed with the seasons ${ }^{12}$. Wigi circulates 25 times during the day and 25 times during the night. Therefore, if the lengths of daytime and nighttime changed, the speed of circulation also changed. To calculate the speed of Wigi quantitatively, the records of the daytime and nighttime periods ${ }^{5}$ over the 24 Chinese seasons from the Book of Hou Han (後漢書) were used. The speed of Wigi during daytime circulations was calculated by dividing the 25 circulations by daytime length. The speed at night was calculated by dividing the 25 circulations by nighttime length. The unit of speed is cycles/Gak. The results are shown in Table 3. In the calculations, because the speeds were simply determined by dividing the number of circulations by time and are simply averaged values, the results do not reflect any potential variation in speed during the daytime or nighttime. The length of modern daytime is 5 Gak less than it was during the Hou Han dynasty because modern daytime does not include the $2.5 \mathrm{Gak}$ before sunrise and after sunset. The 24 
Table 3. Length of Daytime and Nighttime in 24 Seasons and the Speed of Wigi

\begin{tabular}{|c|c|c|c|c|}
\hline 24 Chinese seasons & Length of daytime & Length of nighttime & $\begin{array}{l}\text { Speed of Wigi in } \\
\text { daytime (cycle/Gak) }\end{array}$ & $\begin{array}{l}\text { Speed of Wigi in } \\
\text { nighttime (cycle/Gak) }\end{array}$ \\
\hline J1 (冬至) & 45 Gak & 55 Gak & 0.556 & 0.455 \\
\hline J2 (小寒) & 45 Gak 8 Bun & 54 Gak 2 Bun & 0.546 & 0.461 \\
\hline J3 (大寒) & 46 Gak 8 Bun & 53 Gak 2 Bun & 0.534 & 0.470 \\
\hline J4 (立春) & 48 Gak 6 Bun & 51 Gak 4 Bun & 0.514 & 0.486 \\
\hline $\mathrm{J} 5$ (雨水) & 50 Gak 8 Bun & 49 Gak 2 Bun & 0.492 & 0.508 \\
\hline J6 (驚蟄) & 53 Gak 3 Bun & 46 Gak 7 Bun & 0.469 & 0.535 \\
\hline J7 (春分) & 55 Gak 8 Bun & 44 Gak 2 Bun & 0.448 & 0.566 \\
\hline J8 (淸明) & 58 Gak 3 Bun & 41 Gak 7 Bun & 0.429 & 0.600 \\
\hline J9 (穀雨) & 60 Gak 5 Bun & 39 Gak 5 Bun & 0.413 & 0.633 \\
\hline J10 (立夏) & 62 Gak 4 Bun & 37 Gak 6 Bun & 0.401 & 0.665 \\
\hline J11 (小滿) & 63 Gak 9 Bun & 36 Gak 1 Bun & 0.391 & 0.693 \\
\hline J12 (芒種) & 64 Gak 9 Bun & 35 Gak 1 Bun & 0.385 & 0.712 \\
\hline J13 (夏至) & 65 Gak & 35 Gak & 0.385 & 0.714 \\
\hline J14 (小暑) & 64 Gak 7 Bun & 35 Gak 3 Bun & 0.386 & 0.708 \\
\hline J15 (大暑) & 63 Gak 8 Bun & 36 Gak 2 Bun & 0.392 & 0.691 \\
\hline J16 (立秋) & 62 Gak 3 Bun & 37 Gak 7 Bun & 0.401 & 0.663 \\
\hline J17（處暑） & 60 Gak 2 Bun & 39 Gak 8 Bun & 0.415 & 0.628 \\
\hline J18 (白露) & 57 Gak 8 Bun & 42 Gak 2 Bun & 0.433 & 0.592 \\
\hline J19 (秋分) & 55 Gak 2 Bun & 44 Gak 8 Bun & 0.453 & 0.558 \\
\hline J20 (寒露) & 52 Gak 6 Bun & 47 Gak 4 Bun & 0.475 & 0.527 \\
\hline J21（霜降） & 50 Gak 3 Bun & 49 Gak 7 Bun & 0.497 & 0.503 \\
\hline J22 (立秋) & 48 Gak 2 Bun & 51 Gak 8 Bun & 0.519 & 0.483 \\
\hline J23 (小雪) & 46 Gak 7 Bun & 53 Gak 3 Bun & 0.535 & 0.469 \\
\hline J24（大雪） & 45 Gak 5 Bun & 54 Gak 5 Bun & 0.549 & 0.459 \\
\hline
\end{tabular}

J1 J24: Chinese 24 seasons (J1: winter solstice, J13: summer solstice).

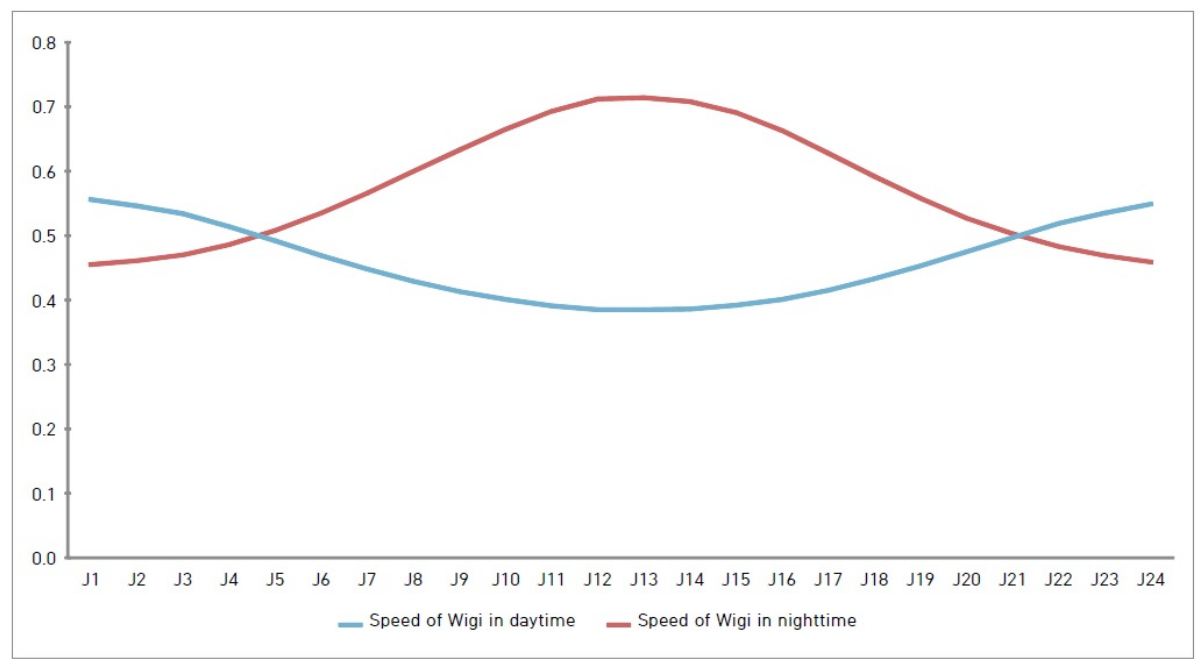

Fig. 1. Speed of Wigi in Chinese 24 seasons.

Horizontal axis: 24 seasons, Vertical axis : speed of Wigi (cycles/Gak). seasons are named using the alphabet characters J1 to J24. $\mathrm{J} 1$ is the winter solstice, $\mathrm{J} 7$ is the spring equinox, J13 is the summer solstice, and J19 is the autumnal equinox. According to the research of Needham, J., Wang, L. ${ }^{4}$, Soma, M, Kawabata, $\mathrm{K}$, and Tanikawa, $\mathrm{K}^{5}$, the measurements for daytime and nighttime during the Han era were performed in the region of Yang Cheng (陽城, latitude 34 degrees, $43 \mathrm{~min}$ ), which is near Luo Yang (洛陽, latitude 34 degrees 75 min) in China ${ }^{14)}$. Fig. 1 shows the speed of Wigi in the daytime and nighttime following the 24 seasons, and were calculated using the data 
from the Book of Hou Han. The horizontal axis indicates the 24 seasons and the vertical axis indicates Wigi speed. The unit of speed is cycles/Gak. Wigi speed in the daytime is the fastest when the daytime period is the shortest (the winter solstice, J1); speed is about 0.556 cycles/Gak. Wigi speed in daytime is the slowest when the daytime period is the longest (summer solstice, J13); speed is about 0.385 cycles/Gak. Wigi speed in the nighttime is the fastest when the nighttime period is the shortest (the summer solstice, J13); about 0.714 cycles/Gak. The speed in nighttime is the slowest when the nighttime period is the longest (the winter solstice, J1); about 0.455 cycles/Gak. In Table 3 and Fig. 1, when Wigi speed increases in the daytime, its speed in the nighttime decreases, and vice versa. The difference of speeds between the daytime and nighttime is the biggest on the day of the summer solstice when the speed arrives at the maximum at nighttime and the minimum at daytime.

\section{Daytime does not begin at the time of sunrise but at dawn (2.5 Gak before sunrise)}

Original text: "The fact is: At dawn when the yin (qi) are exhausted, the yang qi appear in the eyes. When the eyes widen, then qi ascend into the head” (是故, 平旦陰盡, 陽氣出於 目, 目張則氣上行於頭).

"It follows: The early morning is the starting point. When the night ends that is the beginning” (然後常 以本旦爲紀, 以夜 盡爲始 $)^{2)}$.

The first text states that at the time of the dawn, the Yang qi occurs and the eyes open. The second text translates the words, 平旦 as the early morning but the original Chinese meaning of 平旦 is dawn. It is not sunrise but the time of dawn, which is 2.5 Gak before sunrise ${ }^{5,14}$. This is in correlation with the Book of Hou Han. It is not clear why the ancient Chinese decided that dawn was the time when daytime began. However, Jegayoksangjip (諸家曆象集, The Collection of all kinds of Astronomical Calendars and Celestial Images) states that at the era of Huang Di (黃帝, Yellow Emperor) it brightens from 2.5 Gak before sunrise and darkens at $2.5 \mathrm{Gak}$ after sunset ${ }^{14)}$, and $5 \mathrm{Gak}$ is added. Therefore, considering the meaning of the texts of the chapter and the astronomical concepts, Wigi begins to circulate in the Yang portion from dawn and not from sunrise. The dawn is the time when Yang appears. There are some examples in Chinese medicine that show that Yang is related to symptoms that appear at dawn. One example is dawn diarrhea (五更瀉, Wu Geng Xie, Ogyongsa), which happens at dawn. The deficiency of the Kidney Yang is the main cause of dawn diarrhea $^{15,16)}$.

However, the next piece of the original text states that "In the course of one day and one night, the water in the clepsydra descends by 100 marks. 25 marks are the measure of half a day. That is always so, and will never end. When the sun goes down, (daytime) ends" (一日一夜, 水下百刻, 二十五 刻者, 牛日之度也, 常如是冊已, 日入而止 $)^{2)}$. The English text translates 日入而止 as “When the sun goes down, (daytime) ends." The translation ignores the time of 2.5 Gak that occurs after sunset. However 2.5 Gak is only about 36 minutes and it can be easily ignored. Considering the ancient Chinese astronomical concepts and the previous text, it is not likely that the author of the "Wigi Haeng" chapter really meant daytime ends at the moment of the sunset. 日入 can be translated as $2.5 \mathrm{Gak}$ after sunset rather than just sunset.

According to the Book of Hou Han, the shortest period of the daytime is $45 \mathrm{Gak}$ (the winter solstice) and the longest daytime period is 65 Gak (the summer solstice) during one year. Because one day is $100 \mathrm{Gak}$, there is more daytime periods than nighttime periods in one year. Because daytime is Yang, and nighttime is Yin, more research is needed to determine if ancient Chinese people thought that there were more Yang than Yin in nature.

\section{The last paragraph of the chapter does not agree with the general concepts of Wigi}

Original text: "When the water (in the clepsydra) has fallen by one mark, the qi of man are in the major yang (conduit). When the water (in the clepsydra) has fallen by two marks, the qi of man are in the minor yang (conduit). When the water (in the clepsydra) has fallen by three marks, the qi of man are in the yang brilliance (conduit). When the water (in the clepsydra) has fallen by four marks, the qi of man are 
in yin section” (水下一刻, 人氣在太陽, 水下二刻, 人氣在少陽; 水下 三刻, 人氣在陽明; 水下四刻, 人氣在陰分 $)^{2)}$.

This text states that Wigi completes one cycle in $4 \mathrm{Gak}$ and each cycle includes the circulation of the Yin portion. In that way, only 25 cycles would be completed in a day and even in the daytime, Wigi passes the Yin portion in each cycle. This does not agree with the concepts of the movement of Wigi. This speed of circulation is too slow to complete 50 cycles in a day. At the lower latitude, the daytime speed of Wigi slows because the length of daytime increases but no matter the latitude, it is impossible to find a place where Wigi circulates through 1 cycle in 4 Gak.

\section{Discussion}

The author of the "Wigi Haeng" chapter tried to use knowledge of ancient Chinese astronomy in its writing and the chapter reflects the idea of communication between humans and the universe. However, the irregularity of the angular distances of $28 \mathrm{Su}$ was not much considered in the chapter.

The author of the chapter did not mention that the speed of Wigi changes but did mention that the durations of daytime and nighttime change depending on the seasons. This indicates that the author knew that the speed of Wigi changes. It is also possible that the Wigi speed changes during the daytime or the nighttime depending on the time as well. For example, the speed at 10:00 may be different from the speed at 16:00. This concept was not mentioned in the chapter but it is worth investigating in the future.

One day is 1440 minutes and the Wigi circulates 50 cycles a day. Therefore, the time for the Wigi to circulate one cycle is 28.8 minutes on average. That is why most acupuncturists leave needles in for about 30 minutes after they insert them. However, if the speed of Wigi varies depending on the seasons and the durations of the daytime and nighttime, the leaving time for needles has to be changed depending on these factors.

\section{Conclusion}

1. The names of constellations have changed and it reflects the writing period of the "Wigi Haeng" chapter.

2. The angular distances of the $28 \mathrm{Su}$ are irregularly different; however, the author of the "Wigi Haeng" chapter did not consider them.

3. The commentary of Taeso about the constellations is correct.

4. The speed of Wigi changes depending on the seasons. and the speed at daytime is the fastest during the winter solstice ( 0.556 cycles/Gak) and the slowest during the summer solstice ( 0.385 cycles/Gak). The speed at nighttime is the fastest during the summer solstice ( 0.714 cycles/Gak) and the slowest during the winter solstice ( 0.455 cycles/Gak). When the daytime speed increases the nighttime speed decreases and vice versa. ( 1 Gak=0.24 hour) The difference of speeds in the daytime and the nighttime is the biggest on the day of the summer solstice when the speed arrives at the maximum at nighttime and the minimum at daytime.

5. The daytime does not begin at the time of sunrise but at dawn (2.5 Gak before sunrise). Therefore, Wigi begins to circulate in the Yang portion at the time of dawn. The nighttime begins $2.5 \mathrm{Gak}$ after sunset. Therefore, Wigi begins to circulate in the Yin portion $2.5 \mathrm{Gak}$ after sunset. (2.5 Gak= 36 minutes)

6. This chapter explains how the Wigi moves in the human body and emphasizes that the acupuncture treatments follow the movement of Wigi. Because acupuncture treatments are done following the movement of Qi, the exact time when Wigi enters the Yang portion and Yin portion is important.

7. The speed of Wigi changes depending on the seasons and the leaving time of needles must be modified depending on these factors.

8. The true meaning of this chapter is that the acupuncture treatments have to be done considering the movement of Wigi, which is influenced by the movement of the universe. The location of Wigi is different in the day and night times. Therefore, acupuncture treatments must be done differently depending on the time of day. Treatments are 
therefore suggested to occur more on Yang channels in the daytime and more on Yin channels in the nighttime. That is the typical of the idea of communication between humans and the universe or the union of humans and the universe, ideas that dominated ancient Chinese understandings of astronomy and medicine.

\section{Acknowledgement}

None.

\section{Funding}

None.

\section{Data availability}

The authors can provide upon reasonable request.

\section{Conflicts of interest}

The author has declared that no competing interests exist.

\section{References}

1. Zhu, S. Influence of the Taoist philosophy on Chinese Medicine, Shandong Zhongyiyao Daxue Xuebao (Journal of Shangdong University of Traditional Chinese Medicine), 1990 ; $1: 3$.

2. Unschuld, P, Huang Di Nei Jing Ling Shu. University of California Press, Oakland, 2016 ; 704, 705, 699-701, 701-2, 702-4, 704-5, 706-9.

3. Wang, H.(chief editor), Lecture on Neijing, Beijing, People's
Medical Publishing House Co., 2002; 5, 1-2, 3.

4. Needham, J., Wang, L., Science and Civilisation in China vol.3, Mathematics and the Sciences of the Heavens and the Earth, Cambridge, Cambridge University Press, 1959; 284, 287.

5. Soma, M., Kawabata, K., Tanikawa, K., Units of Time in Ancient China and Japan, Publications of Astronomical Society of Japan (PASJ), 2004 ; 56(5) : 887, 889-90, 891. https://doi.org/10.1093/ pasj/56.5.887

6. Kim, I., History of the sky, Oriental Astronomical thought, Seoul, Yemoonseowon, 2007 ; 199, 200, 152.

7. Oosaki, S., History of the constellations in China, Tokyo, Yuzankaku, 1987; 20, 2, 5, 4.

8. Wu, L. and Wu, Q., Yellow Emperor's canon of Internal Medicine, Beijing, China Science and Technology Press, 2002 ; 799.

9. Wang, J., Liang, Z., Wang, S., Pictorial image of the $28 \mathrm{Su}$, dragon and the white tiger from the tomb of Zeng Hou Yi,, Wenwu (Cultural Relics Publishing House), 1979; 7 : 40, 42-3.

10. Lee, S. (Chosun dynasty), The Collection of all kinds of Astronomical Calendars and Celestial images vol.1 (Jegayoksangjip vol.1), Seoul, Sejong daewang ginyom sauphyo, 2013 ; 153-4.

11. Yang, S.(Compilation and commentaries), Huang Di Nei Jing Tai Su, Beijing, People's Medical Publishing House Co. LTD, 1965 ; 213, 214, 215.

12. Lee, N., Research on the chapter, 'The movement of Wigi' in Youngchu', The Journal of Korean Medical Classics, 1997 ; 10 : $5,6,18,14,22,27$.

13. Wang, Z., Analysis of the debate of 'Yang is easily in excess' and 'Yang is never in excess' and its meanings in clinical treatment and maintenance of health, Zhongguo minjian liaofa, 2007 ; 15(3) : 3 .

14. Lee, S.(Chosun dynasty), The Collection of all kinds of Astronomical Calendars and Celestial images vol.2 (Jegayoksangjip vol. 2), Seoul, Sejong daewang ginyom saup hoi, 2013; 211, 225.

15. Deng, T. (Chief editor), Chinese Medicine Diagnosis, Shanghai, Shanghai Scientific and Technical Publishers, $2001 ; 57$

16. Lee, B., Oriental Medical Diagnosis (Hanbang Jindanhak) vol.1, Seoul, Sungbosa, $1986 ; 148-9$. 